\title{
As Alterações dos Modelos de Gestão Estatal e uma Proposta de Conceituação de Governança da Administração Pública
}

\author{
The Changes to the State Management Models and a Proposal for a Concept of \\ Governance of Public Administration
}

\author{
Mateus Bertoncini ${ }^{1}$ \\ Vinícius Rafael Presente ${ }^{1}$ \\ ${ }^{1}$ Centro Universitário Curitiba, Curitiba, PR, Brasil
}

\begin{abstract}
Resumo: O presente trabalho tem como objetivo analisar em que medida as transformações nas formas de gestão estatal e a crise do modelo de Estado moderno contribuíram para o surgimento de uma noção de governança da Administração Pública. Para tanto, utilizando-se do método indutivo e de pesquisa bibliográfica, será elaborado um retrospecto dos modos de gestão estatal, a fim de propor uma conceituação de governança da Administração Pública.
\end{abstract}

Palavras-chave: Gestão Estatal. Crise do Modelo de Estado Moderno. Governança da Administração Pública.

\begin{abstract}
The present work aims to analyze to what extent the transformations in the forms of state management, as well as the crisis of the modern State model contributed to the emergence of a notion of governance of the Public Administration. To do so, using the inductive method and bibliographic research, a retrospective of the modes of state management will be elaborated, in order to propose a governance concept of Public Administration.
\end{abstract}

Keywords: State Management. The Crisis of the Modern State Model. Governance of Public Administration.

Recebido em: 17/04/2020

Revisado em: 10/10/2020

Aprovado em: 11/11/2020 


\section{Introdução}

A construção de uma noção de governança da Administração Pública está atrelada à compreensão das alterações dos modelos de gestão estatal, em especial o movimento de transposição do modelo burocrático, pautado por uma racionalidade jurídico-formal proposta por Max Weber, pela reforma do Estado concebida por um movimento conhecido como gerencialismo, ou ainda como New Public Management, em vias de sua aproximação com práticas de gestão típicas da iniciativa privada, pautada na busca pela eficiência, até seu declínio.

Muito embora o gerencialismo estivesse preocupado com a eficiência administrativa, o que se verificou, não só no Brasil, foram efeitos contrários ao que se propunha. A partir dessa constatação dá-se a construção de um projeto de governança da Administração Pública, como superação do modelo gerencial.

Importante destacar que, como ainda não existe um conceito de governança da Administração Pública bem estabelecido e aceito pela literatura especializada (FUKUYAMA, 2013, p. 2), a construção que se propõe adota uma perspectiva analítica da governança, preocupada com a existência de mecanismos suficientes para que a atuação governamental seja efetiva, em detrimento de uma abordagem prescritiva-formal, preocupada com a formulação de um pacote de medidas ou de reformas predeterminadas (CAVALCANTE; PIRES, 2018, p. 8-10).

Por intermédio da análise do histórico das formas de gestão do Estado moderno, passando pela crise experimentada pelo gerencialismo, implementado a partir da década de 1990, é que se chegará às origens e às bases da governança pública, na perspectiva não apenas comparativa de ambos os modelos, mas também na indutiva senda de proposição de uma conceituação de governança da Administração Pública.

A atualidade do tema e a sua relevância são aspectos fora de questão, pois a crise do Estado brasileiro também é uma crise de Administração Pública e, portanto, algo que exige o esforço da doutrina no apontamento dos caminhos possíveis para a sua equação, na perspectiva de que o projeto constitucional de construção de uma sociedade livre, justa e 
solidária não se inviabilize pela ausência de uma boa Administração Pública, cujos modelos burocrático e gerencial não deram conta, ao menos no que se refere à demanda por serviços públicos de uma população reconhecidamente carente.

Em suma, o que é governança da Administração Pública?

Embora o cientista deva ser crítico e cauteloso, compreender no plano jurídico a governança da Administração Pública é algo importante e que pode contribuir para a solução de parcela - ainda que pequena - dos problemas de gestão pública no Brasil, intimamente relacionados com as demandas por cidadania.

\section{Formas de Gestão do Estado: do Patrimonialismo ao Modelo Gerencial}

Em vistas de realizar o percurso histórico a fim de chegar próximo de uma noção de governança da Administração Pública, é necessário retomar o momento de advento do Estado Liberal, recorte histórico que tem como marco a Revolução Francesa. Até então imperava o patrimonialismo no qual o Estado e, por consequência, sua administração faziam parte dos bens do monarca e estavam submetidos à sua vontade e disposição.

O advento do Estado Liberal representou a superação do modelo patrimonialista por uma forma de gestão estatal submetida ao julgo da legalidade, limitando o exercício do poder, para que estivesse prescrito pela legislação. Com a deposição do rei Luís XVI foi necessário encontrar um outro titular da soberania. A solução dada pela burguesia foi a de instalar uma Assembleia Nacional atribuindo-se ao povo a soberania, exercida por meio de seus representantes, cuja vontade popular encontrou sua expressão maior na lei (COMPARATO, 2014, p. 1.121).

Tendo em vista que o Estado de tipo liberal é fruto da ascensão da burguesia, a limitação do poder pela lei tem como razão de ser a necessidade de previsibilidade e calculabilidade das ações estatais, o que confere certo grau de certeza ao mercado e, por consequência, cenário favorável ao desenvolvimento da atividade mercantil (GRAU, 2017, p. 16-18). 
Isso implicou na necessidade de um arranjo do ordenamento jurídico e de uma nova conformação estatal, que privilegiasse a atividade econômica (GRAU, 2017, p. 16).

Ou seja, visto que "[...] a economia mercantil capitalista que exige que os negócios oficiais da administração sejam feitos com precisão, sem ambiguidade, continuamente, e com a maior velocidade possível [...]" (WEBER, 1963. p. 250), foi necessário adotar um modelo de gestão que, ao contrário do que ocorria no modelo patrimonialista, despersonalizasse a atividade estatal e garantisse que as decisões da Administração Pública fossem previsíveis e adotadas de acordo com as regras estabelecidas pelo Poder Legislativo, incumbido de exercer a soberania em nome de seu novo titular, o povo.

Para atender a esses anseios, adotou-se o modelo burocrático de gestão, por meio do qual a estrutura estatal é fragmentada e estruturada em órgãos, de maneira rígida e hierarquizada, de modo que cada uma das atividades, de acordo com a especialidade da matéria, é desempenhada por um órgão específico, detentor de um feixe de competências instituído em lei e que são exercidas por um servidor público. A proposta do modelo burocrático, em suma, é a de que o funcionamento do Estado e a realização de suas atividades sejam feitas de maneira impessoal, não suscetível a sentimentos subjetivos e de modo técnico, por agentes especializados (SCHIER, 2004, p. 25-26).

A burocratização oferece, acima de tudo, a possibilidade ótima de colocar-se em prática o princípio da especialização das funções administrativas, de acordo com as considerações exclusivamente objetivas. Tarefas individuais são atribuídas a funcionários que tem treinamento especializado e que, pela prática constante, apreendem cada vez mais. O cumprimento "objetivo" das tarefas significa, primordialmente, um cumprimento de tarefas segundo regras calculáveis e "sem relação com pessoas". (WEBER, 1963, p. 250)

Em um Estado Liberal não se admite a intervenção estatal na economia, este é o campo de atuação reservado aos particulares, autorregulado pelas regras do mercado, para atuação de seus integrantes. A função do 
Estado se restringe a garantir que o mercado funcione livremente, sem sua interferência ou ingerência, atrelado à uma concepção de Estado mínimo, que deve manter estrutura suficiente para o exercício das poucas funções que lhes são atribuídas, particularmente aquelas atinentes à garantia das liberdades e da segurança dos indivíduos (FINGER, 2004, p. 70).

Contudo, em razão do mal funcionamento do livre mercado, em especial pelo que se verificou no início dos anos 1930 com a Grande Depressão ${ }^{1}$, entrou em crise o modelo econômico do liberalismo pautado na autorregulamentação e, por consequência, o modelo de gestão estatal que lhe dava suporte: o Estado Liberal.

Uma das respostas à crise do Estado Liberal foi o surgimento do Estado Social ${ }^{2}$, também chamado de Estado Socialdemocrata ou Estado Providência, preocupado com os direitos sociais dos cidadãos e com a promoção do desenvolvimento econômico, assumindo um papel de planejamento da economia e tomando para si a prestação de comodidades materiais. É dizer que

\footnotetext{
${ }^{1}$ Muito embora não seja a intenção do presente trabalho analisar as razões históricas e/ou econômicas que culminaram na chamada Grande Depressão, ou ainda discorrer de maneira pormenorizada sobre os impactos sofridos pelos países em toda extensão do globo terrestre, diante de sua significância para história do século XX, importante assinalar que a Grande Depressão representou um colapso no sistema capitalista durante o período entreguerras. Nas palavras do historiador Eric Hobsbawm (1995, p. 91): "Em suma, o mundo da segunda metade do século XX é incompreensível se não entendermos o impacto do colapso econômico [...]. Mas a Primeira Guerra Mundial foi seguida por um tipo de colapso verdadeiramente mundial, sentido em pelo menos todos os lugares em que homens e mulheres se envolviam ou faziam uso de transações impessoais de mercado. $\mathrm{Na}$ verdade, mesmo os orgulhosos EUA, longe de serem um porto seguro das convulsões de continentes menos afortunados, se tornando o epicentro deste que foi o maior terremoto global medido na escala Richter dos historiadores econômicos - Grande Depressão do entreguerras. Em suma: as guerras, a economia mundial capitalista pareceu desmoronar. Ninguém sabia exatamente como se poderia recuperá-la". "O período de 1929-33 foi um abismo a partir do qual o retorno a 1913 tornou-se não apenas impossível, como impensável. O velho liberalismo estava morto, ou parecia condenado" (HOBSBAWM, 1995, p. 111).

${ }^{2}$ Para além do surgimento do Estado Sociademocrata, sobrevieram, também, como resposta à Grande Depressão o comunismo marxista e o fascismo, tendo sido a primeira opção a que se demonstrou mais viável (HOBSBAWM, 1995, p. 111-112).
} 
[...] o Estado tornava-se social um Estado Social-Burocrático na medida em que, para promover o bem-estar social e o desenvolvimento econômico, contratava diretamente, como funcionários públicos, professores, médicos, enfermeiras, assistentes sociais, artistas, etc. (BRESSER-PEREIRA, 1998, p. 55)

Apesar da adoção de um Estado Social, o modelo de gestão do Estado Liberal, qual seja, o modelo burocrático, foi mantido, pois com a Administração Pública imbuída de prestar um número muito maior de atividades aos administrados eram necessários mecanismos de gestão racional e impessoal, para que não houvesse falha nos serviços prestados e para que eles fossem realizados de maneira uniforme. Para tanto, havia a necessidade de seu desempenho por servidor público especializado e habituado com a sua prestação. Além disso, a gestão burocrática permite a realização de um controle procedimental pelas autoridades hierarquicamente dispostas, a fim de verificar o atendimento às regras de prestação de cada um dos serviços públicos.

Contudo, a partir dos anos 1970, o Estado Social enfrentou uma forte crise fiscal que diminuiu, ou mais drasticamente, impediu que continuasse exercendo suas funções e atividades, pois as receitas arrecadadas passaram a ser inferiores aos gastos para manutenção de sua estrutura.

O exaurimento financeiro do Estado Social inaugurou um processo dialético na tensão entre Estado mínimo e Estado máximo. Os modelos econômicos de um e outro representam a síntese do embate entre a amplitude limitada dos benefícios sociais e os recursos vertidos para provê-los, tantas vezes de modo insatisfatório. (OLIVEIRA, 2014, p. 337)

Ao passar de garantidor da segurança e das liberdades para prestador de serviços públicos, o Estado protetor dos direitos sociais e ordenador da economia teve de incrementar o seu aparato administrativo burocrático para ter condições materiais de desempenhar todas essas atividades. $\mathrm{O}$ aumento da estrutura burocrática implicou em progressiva majoração orçamentária, em razão das despesas para sua manutenção, aí incluídos não só as contrapartidas relativas aos subsídios do funcionalismo 
público, mas também os custos de manutenção da infraestrutura física e o montante despendido para aquisição dos insumos inerentes à prestação de cada um dos serviços públicos.

Os gastos para manutenção de todo o aparato indispensável ao Estado Social e a impossibilidade de incremento de receita da Administração Pública, que não estivesse associada à majoração da carga tributária, levaram o Estado à uma situação de insolvência e de crise fiscal. Atingiu-se um momento de grandes dificuldades para que o Estado mantivesse o cumprimento de suas obrigações, a realização de novos investimentos e/ou implementação de novas políticas públicas (BRESSER-PEREIRA, 1998, p. 78).

Neste momento, em que era necessário encontrar uma saída para a estagnação estatal causada pela crise fiscal, a fim de ser retomada a capacidade de ação do Estado e sua eficiência administrativa, ganharam força os que defendiam que a Administração Pública burocrática não era vocacionada para lidar com os avanços técnicos já atingidos e que era necessário instituir uma prática de gestão da Administração Pública mais modernas, mais eficientes e mais preocupadas com o cidadão (BRESSER-PEREIRA, 2000, p. 17).

Diante de uma nova crise e identificadas as suas causas foi necessário adotar medidas para conter os gastos da Administração Pública, para que fossem equacionados os problemas orçamentários, reduzir a intervenção do Estado no domínio econômico e social, além de garantir mais eficiência à gestão estatal. Foi neste cenário que surgiu o gerencialismo, sob a influência do neoliberalismo.

Muito embora seja possível afirmar que o pensamento neoliberal tenha despontado na Europa em meados dos anos 1940 e tenha ganhado corpo no final desta mesma década ${ }^{3}$, foi somente no raiar da década de

\footnotetext{
${ }^{3}$ Perry Anderson marca como data de origem do pensamento neoliberal a publicação da obra de Friedrich Hayek, O Caminho da Servidão, no ano de 1944. Como marco do ponto de partida de sua ascensão aponta a fundação da Sociedade Mont Pèlerin, no ano de 1947, oriunda de uma reunião convocada por Heyek, que ocorreu na estação de esqui de mesmo nome, localizada na Suíça, e que reuniu pensadores contrários ao Estado Social. Participaram da reunião e da fundação da Sociedade Mont Pèlerin nomes como Milton
} 
1980, com a eleição de Margareth Tatcher, na Inglaterra, e Ronald Reagan, nos Estados Unidos, que seus fundamentos passaram a ser postos em prática (ANDERSON, 1995, p. 9-11).

O pensamento tem sido duramente criticado pelos defensores do Estado de bem-estar social, que o acusam de menosprezar o modelo Social e de serem ferrenhos na defesa de uma matriz econômica sem qualquer intervenção do Estado, despreocupados com os direitos sociais e que promove a desigualdade e o empobrecimento de grande parcela da população (ANDERSON, 1995, p. 18).

Aponta-se que os países periféricos ou semiperiféricos foram os mais afetados pelas alterações promovidas em razão do ideário neoliberal, seja porque foram submetidos à imposição de políticas de ajustamento de sua estrutura a padrões previamente estabelecidos como condição para renegociação de suas dívidas externas e acesso a financiamento estrangeiro. Além disso, em razão da instalação em seus territórios de empresas multinacionais, sofreram com o impacto da formação de uma nova classe social, inserida em uma escala de desigualdade mundial (SANTOS, 2002, p. 31).

Ainda no campo das críticas ao modelo do neoliberalismo, existem aquelas que apontam para uma dominação não política dos Estados periféricos pelos ditos Estados centrais, revelada por intermédio de "três consensos", todos oriundos do Consenso de Washington: Estado fraco; democracia liberal; e o primado do direito e do sistema judicial.

Sob essa perspectiva crítica, o consenso do Estado fraco está baseado na ideia de que existe uma oposição e uma relação de inimizade entre o Estado e a sociedade civil. Tendo em vista que o modelo econômico neoliberal precisa que a sociedade seja forte para se desenvolver, por conseguinte é necessário que o Estado seja fraco, fragilização obtida por meio de sua diminuição. O que se busca é um Estado mínimo, tal como o Estado Liberal, daí a necessidade de adoção de medidas de desregulamentação da economia e de privatização.

Friedman, Karl Popper, Ludwig von Mises, Walter Lipman, Salvador de Madariaga, entre outros (ANDERSON, 1995, p. 9-10). 
Já o consenso relativo à democracia liberal estaria preocupado em dar uma forma política ao Estado franco, de modo a garantir-se apenas as liberdades política e econômica (mercado livre) e eleições livres. A intervenção do Estado em outros tipos de atividades seria simplesmente dispensada e rechaçada, pois a construção do bem comum é atribuição dos particulares e da própria sociedade.

Por sua vez, o consenso do primado do direito e do sistema judicial, que melhor vincula a globalização política e a globalização econômica, consiste no implemento de normas jurídicas que garantam a liberdade dos mercados e a previsibilidade da atuação estatal, além da existência de um sistema judicial eficaz e apto a aplicar as sanções pelo inadimplemento contratual (SANTOS, 2002, p. 41-43).

As reformas gerenciais têm como âmbito de surgimento, de modo mais evidente, os países anglo-saxões, em especial os Estados Unidos e a Inglaterra, em virtude, como já dito, da vitória eleitoral de mandatários simpáticos ao pensamento neoliberal e que, para os seus defensores, essa vitória foi necessária para superar a crise fiscal fruto do Estado Social, retomar o desenvolvimento econômico e conferir mais eficiência à Administração Pública.

Um dos principais componentes da reforma de Estado está relacionado com a delimitação de sua área de atuação, na tentativa de solucionar a crise surgida em razão do tamanho do Estado Social. Para a delimitação desse novo modelo de atuação, é necessário dividir as atividades estatais em três grupos, levando em consideração o grau de exclusividade de desempenho pelo próprio Estado ou em razão da identificação de algum interesse estatal em seu desenvolvimento (BRESSER-PEREIRA, 2000).

O primeiro grupo congrega as atividades cujo desempenho deve ser de titularidade exclusiva do Estado, aí incluídas o de manutenção de defesa do território, o exercício do poder de polícia, a administração da justiça, a arrecadação de impostos, a formulação de políticas públicas, a instituição de leis, a manutenção do sistema financeiro, entre outras, todas atividades relacionadas ao exercício de poder e que devem permanecer sob a tutela do Estado, pois somente a ele deve incumbir o exercício da força. 
Em um segundo plano estão as atividades que podem ser classificadas como não exclusivas do Estado. Aquelas que ainda que o Estado Social tenha passado a executá-las não podem ser qualificadas como inerentes às atividades estatais, pois não demandam o uso da força para o seu desempenho, por exemplo, a prestação de serviços de saúde, de educação, de cultura e de pesquisa científica.

Ainda que fora do campo das atividades classificadas como exclusivas, por estarem relacionadas com direitos básicos que devem ser assegurados aos cidadãos e em virtude da dificuldade de desempenho por particulares, com a compensação do preço em forma de lucro, admite-se que o Estado subsidie ou financie o seu desempenho ou transfira sua execução ao terceiro setor.

$\mathrm{O}$ último grupo diz respeito às atividades de produção de bens e serviços para o mercado, campo de atuação que deve ser composto somente de particulares atuando em sistema de competição, o que impõe a privatização de empresas estatais que exercem atividade econômica e a terceirização, pela administração pública, das atividades auxiliares.

Era também necessário empreender uma desregulamentação de setores econômicos, a partir da identificação das áreas em que havia sido imposta uma regulamentação excessiva, para que fosse possível reduzi-la. Apesar disso, não foi possível eliminar a regulamentação por completo, pois existem atividades em que o papel do Estado como regulamentador é essencial, como é o caso das normas de comércio exterior ou de regulamentação ambiental (BRESSER-PEREIRA, 1998, p. 74-75).

Mantida a regulamentação estatal apenas em áreas consideradas como essenciais, ao poder público incumbe realizar a físcalização do cumprimento dos respectivos regulamentos e aplicar as sanções previstas para o caso de seu descumprimento.

A partir desta nova concepção, o Estado deixa de ser o protagonista da atividade econômica devolvendo-a à iniciativa privada, embora não nos padrões vividos na era do Estado Liberal. O Estado Regulador passa a ser agente normativo e regulador da atividade econômica, criando mecanismos para a manutenção da livre concorrência e para coibir abusos, 
atuando como agente econômico somente em casos excepcionais (SILVA, 2007, p. 807).

A atividade fiscalizatória está diretamente ligada ao poder normativo do Poder Público, eis que é necessário para coibir abusos e aplicar as sanções previstas para o descumprimento das normas a que está submetido o agente econômico (SILVA, 2007, p. 808). Em outras palavras pode-se dizer que o Estado deve possuir meios para garantir eficácia às normas que regulamentam a atividade econômica, sendo que estes meios devem possuir amparo legislativo em homenagem ao princípio da legalidade (GRAU, 2015, p. 300-301).

Firme no propósito de reduzir as atribuições do Estado, tendo como norte garantir ao aparelho estatal maior eficiência, era necessário realizar as respectivas alterações institucionais que garantissem a implementação dos propósitos gerenciais. Para tanto, os ideais gerenciais buscaram inspiração no modelo de gestão da iniciativa privada, sob o argumento de que o modo de agir dos particulares conferiria a necessária eficiência que os administradores públicos necessitariam para gerir o Estado.

A inspiração na gestão privada também incluía a crença de que o mercado seria o melhor instrumento para definição de como alocar os recursos públicos, que deveria haver uma competição entre os órgãos e agências públicas, realizada por meio da comparação entre os resultados obtidos por cada um dos órgãos no exercício de suas competências, além da equiparação dos cidadãos à condição de consumidor de serviços públicos. Tudo na tentativa de que a Administração Pública mimetizasse a gestão privada em razão da crença de que assim agindo haveria mais eficiência estatal.

Um resumo do modelo ideal gerencial poderia ser descrito por intermédio dos seguintes caracteres: (i) orientação para clientes e resultados; (ii) flexibilidade; (iii) competitividade administrada; (iv) descentralização; (v) atuação do Estado e não sua ausência completa (como no neoliberalismo puro); (vi) adoção de técnicas de administração privada com vistas à eficiência dos sistemas; (vii) estruturas horizontalizadas; (viii) instituição de agências reguladores 
independentes; (ix) relações administrativas firmadas por contrato de gestão. (GABARDO; ROCHA, 2014, p. 253)

Diversas foram as tentativas de realização de uma reforma do Estado brasileiro para garantir maior eficiência para o exercício das funções da Administração Pública. Em 1964 foi instituída a Comissão Especial de Estudos de Reforma Administrativa, que influenciou diretamente a edição do Decreto-Lei n. 200/1967 e também a criação, em 1979, do Programa Nacional de Desburocratização, que tinha como meta a redução da ingerência Estatal nas atividades privadas e a melhoria da qualidade do atendimento aos cidadãos na prestação dos serviços públicos (GABARDO; ROCHA, 2014, p. 253).

Após esses eventos, no início dos anos 1990, durante o governo de Fernando Collor, que pretendeu uma redução do tamanho da máquina administrativa, promovendo planos de demissão voluntária para os servidores públicos, redução de salários ou, ainda, exoneração sumária. $\mathrm{O}$ ímpeto reformador de Collor foi contido em razão do processo de impeachment. Contudo, isso não fez cessar as críticas ao modelo burocrático da administração brasileira, que estava totalmente descoordenada e aparelhada, de modo a produzir efeitos contrários aos propugnados pelo modelo burocrático (FILGUEIRAS, 2018, p. 74-75) ${ }^{4}$.

Porém, foi a partir de 1995 que a reforma gerencial começou a tomar forma no Brasil, durante o mandato do presidente Fernando Henrique Cardoso e sob a batuta do ministro da Administração Federal e Reforma do Estado, Bresser Pereira. Materializada sob a forma do Plano Diretor da Reforma do Aparelho do Estado, a mudança se deu com a promulgação da Emenda Constitucional n. 19, de 4 de julho de 1998, que dispôs larga-

\footnotetext{
${ }^{4}$ Por razões metodológicas, uma vez que a proposta do presente trabalho não está concentrada nos processos relativos à reforma gerencial da administração pública brasileira empreendida pelo Plano Diretor de Reforma do Aparelho do Estado, ou pelos projetos que lhes são anteriores, mas sim a construção de um conceito mais abrangente de governança pública, não serão realizadas análises detidas a respeito das reformas empreendidas no Brasil. Apesar disso, a sua menção ao longo da exposição tem como objetivo a demonstração de que também o nosso país sofreu os influxos do pensamento neoliberal, que culminou com a reforma gerencial.
} 
mente sobre normas e princípios da administração pública e, dentre outras alterações, fez incluir no caput do artigo 37 a eficiência, preceito maior do gerencialismo.

Muito embora os esforços empreendidos pelos adeptos de um modelo de gestão gerencial ao redor do globo, estando o Brasil incluído nesse rol, os resultados dessas reformas não foram tal como o esperado, na medida em que sua implementação surtiu efeitos diversos e adversos entre os países que a adotaram.

\section{Crise da Concepção Moderna de Estado}

Estudos dedicados à avaliação dos efeitos das reformas gerenciais no continente europeu apontam, no geral, ceticismo quanto às melhoras promovidas por essas alterações. No Reino Unido, em especial, constatou-se que a qualidade das atividades administrativas é inferior àquelas desenvolvidas antes das reformas, além dos custos se apresentarem um pouco superiores (CAVALCANTE, 2017, p. 21-22).

Economicamente, o neoliberalismo fracassou, não conseguiu nenhuma revitalização básica do capitalismo avançado. Socialmente, ao contrário, o neoliberalismo conseguiu muitos dos seus objetivos, criando sociedades marcadamente mais desiguais, embora não tão desestatizadas como queria. Política e ideologicamente, todavia, o neoliberalismo alcançou êxito num grau com o qual seus fundadores provavelmente jamais sonharam, disseminando a simples ideia de que não há alternativa para os seus princípios, que todos, seja confessando ou negando, têm de adaptar-se as suas normas. (ANDERSON, 1995, p. 23)

Críticos mais ferrenhos do pensamento neoliberal sustentam que houve o completo fracasso do gerencialismo, tanto no campo econômico como no campo da gestão pública, pois não atendeu aos objetivos que havia traçado, como a redução drástica do tamanho do Estado e a eficiência representada pelos bons resultados. Ainda nessa linha crítica, diz-se que 
o resultado mais significativo do neoliberalismo teria sido o aumento das desigualdades sociais.

$\mathrm{O}$ insucesso do modelo gerencial pode ser somado à crise da concepção moderna de Estado, verificada a partir no final do século XX, sob o paradigma da pós-modernidade que enfraquece os elementos essenciais para a sua caracterização, a saber ${ }^{5}$ : a ideia de nação, como agrupamento humano que convive de modo solidário no mesmo território; a ideia de que o Estado (e suas estruturas) subsistirá independentemente de quem sejam os governantes; a noção de que o Estado é o ordenador da sociedade, preocupado com o interesse público e com a coesão social e está, em certa medida, apartado da sociedade civil; o monopólio do uso da força, aí compreendida tanto a coerção jurídica (pela instituição de leis que devem ser observadas indistintamente) como a coerção material; estrutura burocrática e compartimentada, com a divisão de tarefas (ou competências) de modo bem delineado (CHEVALLIER, 2009, p. 24-25).

Para Chevallier (2009, p. 25), a globalização e os efeitos do aumento da velocidade da informação são incompatíveis com a rigidez de um modelo de gestão burocrático, já a fragmentação e a concepção de relacionamento em rede não se conformam com a lógica de mercado que permeia o modelo gerencial.

Os efeitos dessas transformações a que foi submetido o Estado tendem a afetar o modelo de Estado Moderno, pois contribuíram para que o conceito tradicional de soberania se tornasse obsoleto, em razão da inter-

\footnotetext{
${ }^{5}$ Não é o objetivo do presente trabalho debruçar-se sobre as divergências e debates a respeito da conceituação de pós-modernidade, contudo, uma vez que para os fins de demonstração da crise do Estado Moderno como condição para o surgimento da concepção de governança estabelecida por Jacques Chevallier, adota-se o conceito registrado por este mesmo autor: "Preferir-se-á aqui falar de 'pós-modernidade', na medida em que se assiste ao mesmo tempo à exacerbação das dimensões já presentes no coração da modernidade e à emergência de potencialidades diferentes: comportando aspectos complexos, mesmo facetas contraditórias, a pós-modernidade se apresenta tanto como uma 'hipermodernidade', na medida em que ela leva ao extremo certas dimensões presentes no cerne da modernidade, tais como o individualismo, e como uma 'antimodernidade', na medida em que ela se desvincula de certos esquemas de modernidade" (CHEVALLIER, 2009. p. 20).
} 
dependência entre os Estados e as organizações internacionais, fruto do processo de globalização incompatível com a ideia de Estado unitário, em razão da fragmentação e degeneração das relações, cada vez mais heterogêneas (CHEVALLIER, 2009, p. 37).

Ainda que o Estado pós-moderno mantenha os seus traços elementares, ele está marcado pela incerteza, pela complexidade e pela indeterminação, características do Estado contemporâneo a que devem corresponder um recíproco modelo de gestão, para que seja possível manter-se as capacidades estatais (CHEVALLIER, 2009, p. 21).

A ordem burocrática, fundada sobre a hierarquização, é desestabilizada pela proliferação de estruturas de um novo tipo, colocadas fora do aparelho de gestão clássico e escapando ao poder da hierarquia. Vê-se delinear um novo princípio de organização do aparelho do Estado, congruente com a ideia de pós-modernidade: enquanto o modelo é do tipo "arborescente" (ele comporta um princípio de unidade, raízes, um centro), a existência de entidades autônomas evoca muito mais a imagem do "rizoma" (G. DELEUZE, F. GUATTARU, 1976) (que não apresenta uma estrutura estável mas se desenvolve a partir das conexões livres estabelecidas entre os seus elementos constitutivos); dispondo de uma capacidade de ação autônoma, essas entidades são religadas umas às outras, não mais por liames verticais de subordinação, mas por relações horizontais de interdependência. A figura pós-moderna da rede tende a partir daí a se substituir àquela de pirâmide. (CHEVALLIER, 2009, p. 99)

Da conjunção entre a insuficiência do Estado gerencial e a crise da concepção moderna de Estado é que surge a concepção de governança pública, como meio necessário para garantir que o Estado, sob o signo da pós-modernidade, consiga exercer suas atividades, ou seja, tenha capacidade de ação dentro deste ambiente fragmentado.

\section{Governança Pública}

Os problemas para as capacidades de atuação da Administração Pública em razão desta transformação sofrida pelo Estado comportam três 
interpretações possíveis. Uma abordagem mais pessimista defende que existe a possibilidade de um total esvaziamento das funções estatais, e que o Estado perderia sua capacidade de formular as políticas públicas, em razão da fragmentação das atividades que hoje são desempenhadas pelo Estado e que seriam transferidas para a sociedade civil. Ou seja, um protagonismo da sociedade e do mercado na condução dos assuntos de interesse geral. De forma mais mitigada, uma segunda abordagem sugere que o Estado permaneceria como entidade central na formulação das políticas públicas, mas perderia sua capacidade de ação que lhe seria retida e, em contrapartida, haveria um incremento de suas atividades regulatórias. Por fim, uma ideia de governança pública sugere que essas alterações no conceito moderno de Estado têm o condão de ampliar as capacidades do Estado (PIRES; GOMIDE, 2016, p. 125).

Esta última conclusão parte de uma noção de relacionamento em rede "[...] que sugere que as relações entre os atores envolvam interdependência, confiança, identidade, reciprocidade e compartilhamento de valores ou objetivos [...]" (PIRES; GOMIDE, 2016, p. 124), o que permite que sejam criados mecanismos de sinergia entre a população e os órgãos do Estado, de modo que estariam superadas as concepções de que o Estado perderia o seu protagonismo na instituição de políticas públicas ou atuaria como mero regulador.

Ao contrário, a ideia de governança proporciona um aumento do protagonismo Estatal, justamente porque ele atuará como o mobilizador dos atores não estatais, para que contribuam para a formulação e implementação das políticas públicas. A colaboração da sociedade civil tem como vantagem a possibilidade de serem colhidas diversas opiniões e sugestões em momento anterior à instituição das políticas públicas, portanto no período de planejamento da administração. Havendo maior participação existe uma redução da possibilidade de que as políticas públicas não atinjam os fins para os quais se propõem, ou seja, a maximização do bem-estar social. Ademais, a imediata verificação do atendimento do interesse público permitirá a adoção de mecanismos corretivos de modo mais célere, caso seja verificado que esse interesse não esteja sendo atendido de modo adequado, justamente em razão da sinergia entre o Estado e a sociedade. 
Sendo esse mecanismo de controle do exercício das atividades estatais também operado pelos cidadãos, é possível inferir que o Estado atuará de modo mais eficiente, pois estará em constante monitoramento da boa execução de suas atividades e será prontamente alertado em caso de execução dissociada ou não suficiente para o atendimento do interesse público.

Esses dois elementos que norteiam a concepção de governança, o relacionamento em redes e o protagonismo dos cidadãos como parceiros da Administração Pública, são suficientes para verificar seu distanciamento do modelo de gestão gerencial.

Quadro 1 - Diferenças entre o Gerencialismo e a Governança Pública

\begin{tabular}{|c|c|c|}
\hline & Gerencialismo & Governança Pública \\
\hline Foco & Cliente/consumidor & Cidadão como parceiro \\
\hline Fonte inspiradora & Lógica de mercado & Redes \\
\hline Crenças fundamentais & Eficiência, competição, contratos & Confiança, reciprocidade \\
\hline Orientação estratégica & $\begin{array}{c}\text { Desagregação, concorrência, } \\
\text { incentivação (pecuniária) }\end{array}$ & $\begin{array}{c}\text { Visão holística e integrada, } \\
\text { colaboração, } \\
\text { profissionalização e inclusão }\end{array}$ \\
\hline Visão do Estado & $\begin{array}{c}\text { Superioridade administrativa do } \\
\text { mercado }\end{array}$ & $\begin{array}{c}\text { Fortalecimento da capacidade } \\
\text { burocrática (interna) }\end{array}$ \\
\hline
\end{tabular}

Fonte: Adaptado de Cavalcante (2017)

Além de tornar mais eficiente a atuação do Estado em razão da colaboração da sociedade, a governança pública se propõe a conferir maior grau de legitimidade democrática às políticas públicas, pois conta com a participação e influência direta da população. Em igual medida, garante o fortalecimento da capacidade dos órgãos da Administração Pública, pois como o Estado não deixa de ser o protagonista no planejamento e na instituição das políticas pública, deverá contar com agentes capacitados para desempenhar essas tarefas.

Em seu mister, os servidores públicos não estarão submetidos a um regime de competição interna, aferida pelo seu grau de produtividade, mas, ao contrário, trabalharão sob o regime de colaboração recíproca, compartilhando informações e valores para que seja possível uma maior 
integração entre os órgãos da administração tendo em vista a preocupação em atender o interesse público.

Esse modelo de gestão permite que seja (re)construída uma relação de confiança entre o Estado e os cidadãos, uma vez que estes perceberão que sua participação contribui e tem efeitos imediatos no planejamento e na instituição das políticas públicas.

De sua parte, o Estado deve implementar mecanismos para manter a confiança que lhe é depositada pelos cidadãos, criando mecanismos para que os agentes públicos prestem contas de suas atividades, garantindo o acesso transparente aos dados do Estado e aplicando as penalidades previstas pelo ordenamento jurídico nos casos de cometimento de ilícitos.

Nesse particular, é importante que a Administração disponha de mecanismos para controle do exercício de suas atividades não somente para que seja possível verificar o atendimento efetivo de suas finalidades, mas para constatar eventuais condutas desviantes e que não estejam em conformidade com a legislação. Aliado aos mecanismos de controle faz-se necessária a existência de mecanismos de integridade, para que a atuação conforme os ditames da probidade permeiem toda a administração pública e condutas ilícitas sejam prontamente verificadas e sancionadas.

Dois organismos internacionais foram de significativa importância para a propagação da ideia de que os Estados deveriam adotar regras de "boa governança" para promover o seu desenvolvimento, a saber, a Organização para a Cooperação e o Desenvolvimento Econômico (OCDE) e o Banco Mundial, ainda na década de 1990.

O Banco Mundial, já no ano de 1992, publicou o relatório intitulado Governança e Desenvolvimento, dedicado ao tema da governança e de sua relação com o desenvolvimento. Mais recentemente, em 2017, o tema da governança pública voltou a ocupar os trabalhos do Banco Mundial, que publicou novo relatório sobre o tema intitulado Governança e a Lei. Desse documento extrai-se o conceito de governança como “[...] o processo por meio do qual atores estatais interagem para conceber e implementar políticas públicas no âmbito de um dado conjunto de regras in- 
formais que moldam e são modeladas pelo poder" (BANCO MUNDIAL, 2017, p. 3).

Muito embora o relatório Governança e a Lei revele uma preocupação com as funções das instituições estatais, parece evidente que o foco principal do Banco Mundial diz respeito às instituições formais e sua modelagem. Nesse sentido, se preocupa com as formas que as instituições devem adotar como práticas de governança de primeira ordem (abordagem tradicional), enquanto a função dos órgãos surge somente mais recentemente como elemento a ser considerado pela governança pública, mas sem que prejudique (ou afaste) a necessidade de serem adotadas as instituições nas formas em que determina. Portanto, ainda que se reconheça a importância das funções desempenhadas, há uma preponderância ao valor atribuído às formas das instituições estatais.

Até agora, a ortodoxia tradicional do desenvolvimento enfatizou a centralidade dessas três premissas na melhoria da governança para o desenvolvimento: a forma das políticas, a capacidade de implementá-las e a aplicação impessoal das regras. Essas premissas moldaram as soluções convencionais da comunidade internacional para problemas do fracasso de políticas nos países em desenvolvimento: primeiro, investir em políticas e leis "boas"; segundo, criar capacidade técnica e organizacional para implementá-las; e terceiro, fortalecer o "estado de direito". (BANCO MUNDIAL, 2017, p. 32)

A preocupação da OCDE, inicialmente, estava dirigida ao estabelecimento de normas de governança corporativa, dirigidas aos agentes econômicos privados. Posteriormente, voltou também os olhos para a necessidade de instituição de normas de governança para a Administração Pública, tendo inclusive patrocinado a celebração de importante convenção para criminalização de pagamento de propina para servidor público estrangeiro em relações comerciais internacionais. Contudo, a OCDE também dá especial atenção e importância ao estabelecimento de estruturas organizacionais formais (FORTINI; SHERMAM, 2017, p. 31-33).

Apesar de não ignorar que em suas formulações de diretrizes de políticas de governança tanto o Banco Mundial quanto a OCDE apontem a 
importância de serem instituídas regras de gerenciamento de riscos, mecanismos de controle, padrões de integridade e de transparência - todos elementos que compõem a concepção de governança - a crítica que se ventila reside no fato de haver uma imposição de padrões formais para a instituição de uma política de governança pública.

Essa concepção prescritiva formal, "[...] notadamente sob a pressão do Banco Mundial, que disso fará a condição para uma 'boa governança', e da OCDE, que erigirá em verdadeira doutrina internacional a reforma administrativa [...]" (CHEVALLIER, 2009, p. 86-87), pode ser apontada como uma abordagem ingênua, que considera que a simples adoção de formas de Estado serão suficientes para suprir as deficiências em sua capacidade de ação (CAVALCANTE; PIRES, 2018, p. 7), além de representar visível ingerência sobre questões referentes à soberania do Estado, uma vez que está relacionada à forma do próprio Estado.

As eventuais alterações na estrutura da Administração Pública devem ser consequência da averiguação realizada por cada país, para que possa se adequar aos preceitos de uma governança pública construída sob uma perspectiva analítica, conforme formulada no tópico anterior, levando em consideração os seus preceitos internos.

Merece destaque que, no ordenamento jurídico brasileiro, o tema da governança da Administração Pública é objeto específico do Decreto n. 9.203, de 22 de novembro de 2017, que pretendeu "[...] tirar o tema da nebulosidade provocada por atitudes pouco efetivas e com certo grau de abstração, a norma formal foca em parametrizar a atuação dos órgãos federais, carregando em seu conteúdo maior segurança jurídica" (CRISTÓVAM; BERGAMINI, 2019, p. 187).

Referido ato normativo elenca os princípios, as diretrizes e os mecanismos de governança pública, além de conter disposições sobre as necessárias adaptações de cunho organizacional da Administração Pública Federal para que tal política seja implantada e mantida em funcionamento. Um dos conceitos apresentados é justamente o de governança pública (artigo $2^{\circ}, \mathrm{I}$ ), definida como o "[...] conjunto de mecanismos de liderança, estratégia e controle postos em prática para avaliar, direcionar e monitorar 
a gestão, com vistas à condução de políticas públicas e à prestação de serviços de interesse da sociedade".

Com efeito, a ideia de governança da Administração Pública está relacionada com o ferramental posto à disposição do administrador para dar efetividade às políticas públicas de forma planejada e controlada para bem prestar os serviços públicos, que compreendem mecanismos de exercício de liderança, definições de estratégias de atuação e mecanismos de controle utilizados como meios de avaliação, direcionamento e monitoramento, sendo que cada um destes elementos é retomado ao longo das demais disposições do Decreto.

\section{Conclusão}

Todo esse arcabouço de práticas, que em conjunto formam a ideia de governança pública, está direcionado a manter a capacidade de atuação do Estado em uma sociedade fragmentada e complexa, para que sua atuação possa conferir certo grau de certeza aos cidadãos.

Em outras palavras, governança pública pode ser entendida como a capacidade que os governos possuem de: assegurar que a vontade dos cidadãos seja capturada nos planejamentos estratégicos, táticos e operacionais; selecionar pessoas e instituir normas e processos adequados para executar as ações planejadas; articular a ação de todos os agentes públicos e privados; alcançar e controlar os resultados previstos; estabelecer indicadores de desempenho para verificar o quanto foi ou não foi alcançado; e divulgar todas essas etapas à sociedade. (NARDES, 2018, p. 137)

Portanto, o conceito de governança da Administração Pública está intimamente relacionado com a instituição de mecanismos que promovam a colaboração e a parceria entre o Estado e a sociedade, baseada na confiança, voltada para a prestação de serviços públicos de modo monitorado, controlado e com verificação de sua efetividade, para bem atender aos anseios da população e que permita a coordenação entre os órgãos da 
Administração Pública, a prestação de contas pelos agentes públicos e a integridade.

A ideia de governança pública parece razoável, como igualmente pareceu razoável a adoção do modelo gerencial na década de 1990. Somente com a sua eventual implementação e a concomitante aferição e controle de seus resultados no tempo adequado é que se poderá avaliar se esse modelo é realmente apto à promoção de políticas públicas, ou se é mais um modismo inadequado financiado pelo contribuinte brasileiro.

\section{Referências}

ANDERSON, Perry. Balanço do neoliberalismo. In. SADER, Emir; GENTILI, Pablo (org.). Pós-neoliberalismo: políticas sociais e o Estado Democrático. Rio de Janeiro: Paz e Terra, 1995. p. 9-23.

BANCO MUNDIAL. Governança e a lei. Washington: Banco Mundial, 2017.

BRESSER-PEREIRA, Luiz Carlos. A crise da américa latina: consenso de Washington ou crise fiscal? Pesquisa e Planejamento Econômico, [s.l.], v. 21, n. 1, p. 3-23, abr. 1991.

BRESSER-PEREIRA, Luiz Carlos. A reforma do Estado dos anos 90: lógica e mecanismos de controle. Revista Lua Nova, São Paulo, n. 45, p. 49-95, 1998.

BRESSER-PEREIRA, Luiz Carlos. Reforma Gerencial do Estado de 1995. Revista de Administração Pública - RAP, Rio de Janeiro, v. 34, n. 4, p. 7-26, jul.-ago. 2000.

CAVALCANTE, Pedro. Gestão pública contemporânea: do movimento gerencialista ao pós-NPM. Brasília: Ipea, 2017.

CAVAlCANTE, Pedro; PIRES, Roberto. Governança Pública: construção de capacidades para efetivação da ação governamental. Brasília: Ipea, 2018.

CHEVALLIER, Jacques. O Estado pós-moderno. Belo Horizonte: Fórum, 2009. 
COMPARATO, Fábio Konder. Poder político e capitalismo. Boletim de Ciências Económicas da Faculdade de Direito da Universidade de Coimbra, homenagem ao Prof. Doutor António José Avelãs Nunes, Coimbra, v. LVII, t. I, p. 1.115-1.144, 2014.

CRISTÓVAM, José Sérgio da Silva; BERGAMINI, José Carlos Loitey. Governança corporativa na Lei das Estatais: aspectos destacados sobre transparência, gestão de risco e compliance. Revista de Direito Administrativo, Rio de Janeiro, v. 278, n. 2, p. 179-210, set. 2019.

FILGUEIRAS, Fernando. Indo além do gerencial: a agenda da governança democrática e a mudança silenciada no Brasil. Revista de Administração Pública - RAP, Rio de Janeiro, v. 52, n. 1, p. 71-55, jan.-fev. 2018.

FINGER, Ana Cláudia. O público e o privado na Administração Pública. In: GUIMARÃES, Edgar (org.). Cenários do Direito Administrativo: estudos em homenagem ao Processor Romeu Felipe Bacellar Filho. Belo Horizonte: Fórum, 2004. p. 57-83.

FORTINI, Cristiana; SHERMAN, Ariane. Governança pública e combate à corrupção: novas perspectivas para o controle da administração pública brasileira. Interesse Público, Belo Horizonte, Ano 19, n. 102, p. 27-44, mar.-abr. 2017.

FUKUYAMA, Francis. "What is Governance?" CGD Working Paper 314. Washington: Center for Global Development, 2013.

GABARDO, Emerson; ROCHA, Iggor Gomes. Burocracia e eficiência administrativa. In: CLĖVE, Clèmerson Merli (coord.). Direito

Constitucional brasileiro: organização do Estado e dos Poderes. São Paulo: Revisa do Tribunais, 2014. v. 2, p. 243-259.

GRAU, Eros Roberto. A Ordem Econômica na Constituição de 1988. 17. ed. Malheiros: São Paulo, 2015.

GRAU, Eros Roberto. Por que tenho medo dos juízes (a interpretação/ aplicação do direito e os princípios). 8. ed. São Paulo: Malheiros, 2017.

HOBSBAWM, Eric. Era dos extremos: o breve século XX - 1914-1991. São Paulo: Companhia das Letras, 1995. 
NARDES, João Augusto Ribeiro. Da governança à esperança. Belo Horizonte: Fórum, 2018.

OLIVEIRA, Fernão Justen de. Serviços Públicos e concorrência. In: CLÈVE, Clèmerson Merlin (coord.). Direito Constitucional Brasileiro: Constituições Econômica e Social. São Paulo: Revista dos Tribunais, 2014. v. 3, p. 335-356.

PIRES, Roberto Rocha Coelho; GOMIDE, Alexandre de Ávila. Governança e capacidades estatais: uma análise comparativa de programas estatais. Revista de Sociologia e Política, Curitiba, v. 24, n. 58, p. 121-143, jun. 2016.

SANTOS, Boaventura de Souza. Os processos da globalização. In: SANTOS, Boaventura de Souza. (org.). A globalização e as ciências sociais. 2. ed. São Paulo: Cortez, 2002. p. 25-102.

SCHIER, Adriana da Costa Ricado. Administração Pública: apontamentos sobre os modelos de gestão e tendências atuais. In: GUIMARÃES, Edgar (org.). Cenários do Direito Administrativo: estudos em homenagem ao Processor Romeu Felipe Bacellar Filho. Belo Horizonte: Fórum, 2004. p. 21-55.

SILVA, José Afonso da. Curso de Direito Constitucional Positivo. 27. ed. Malheiros: São Paulo, 2007.

WEBER, Max. Ensaios de Sociologia. Rio de Janeiro: Zahar, 1963.

Mateus Bertoncini é doutor em Direito do Estado pela Universidade Federal do Paraná (2004). Estágio Pós-Doutoral em Democracia e Direitos Humanos organizado pelo Ius gentium Conimbrigae/Centro de Direitos Humanos (IGC) sediado na Faculdade de Direito na Universidade de Coimbra (2020). Estágio Pós-Doutoral junto ao PPGD da Universidade Federal de Santa Catarina (2014). Professor do Corpo Permanente do Programa de Mestrado e Doutorado em Direito Empresarial e Cidadania do Centro Universitário Curitiba (UNICURITIBA). Procurador de Justiça do Ministério Público do Estado do Paraná. 
E-mail: mateus.bertoncini@unicuritiba.edu.br

Endereço profissional: Rua Chile, n. 1.678, PPGD/UNICURITIBA, Bairro Rebouças, Curitiba, PR. CEP: 80220-181.

ORCID: https://orcid.org/0000-0001-9687-5124

Vinícius Rafael Presente é mestre em Direito pelo Centro Universitário Curitiba (UNICURITIBA), especialista em Direito Administrativo pelo Instituto Romeu Felipe Bacellar.

E-mail: v.r.presente@gmail.com

Endereço profissional: Rua Marechal Hermes, n. 751, Centro Cívico, sede do Ministério Público do Estado do Paraná, Curitiba, PR. CEP: 80.530-230 ORCID: https://orcid.org/0000-0002-2714-3189 